\title{
Distribution of and factors contributing to chronic kidney disease in a middle-aged working population
}

\author{
Yuka Noborisaka $\cdot$ Masao Ishizaki • \\ Yuichi Yamada $\cdot$ Ryumon Honda $\cdot$ Hitoshi Yokoyama • \\ Masaru Miyao $\cdot$ Masaji Tabata
}

Received: 5 February 2013/Accepted: 8 May 2013/Published online: 2 June 2013

(c) The Japanese Society for Hygiene 2013

\begin{abstract}
Objectives To clarify the distribution of chronic kidney disease (CKD) and the factors contributing to its development and progression in middle-aged Japanese workers/ employees.

Methods This was a retrospective study involving 3,964 men and 2,698 women aged 35-64 years in 2009 who had been followed-up until 2003. Data on proteinuria determined with a dipstick and glomerular filtration rate estimated from serum creatinine concentration (eGFR) were collected in the annual health check-ups.

Results Proteinuria was detected in 2.9 and $1.1 \%$ of the men and women, respectively, and total CKD was detected in 16.0 and $16.1 \%$ of the men and women respectively. Moderate or severe CKD associated a high risk of cardiovascular diseases and end-stage kidney disease was
\end{abstract}

Y. Noborisaka $(\varangle) \cdot$ M. Ishizaki · Y. Yamada

Department of Social and Environmental Medicine, Kanazawa

Medical University School of Medicine, 1-1 Daigaku, Uchinada,

Ishikawa 920-0293, Japan

e-mail: hygiene@kanazawa-med.ac.jp

R. Honda

Kanazawa Medical University School of Nursing,

Uchinada, Ishikawa, Japan

H. Yokoyama

Division of Nephrology, Kanazawa Medical University School

of Medicine, Uchinada, Ishikawa, Japan

\section{Miyao}

Graduation School of Information Science, Nagoya University, Nagoya, Aichi, Japan

M. Tabata

Ishikawa Health Service Association, Kanazawa, Ishikawa, Japan found mostly in the male subjects $[2.0$ (men) vs. $0.6 \%$ (women)]. High-risk CKD was found in $3.3 \%$ of the men aged 55-64 years. A body mass index (BMI) of $\geq 30$, hypertension, diabetes mellitus (DM), current smoking and some job types were independently related to the development of proteinuria, while age, BMI, hypertriglyceridemia, and job types were related to total CKD. The development of high-risk CKD was related to preceding mild CKD signs of reduced eGFR and proteinuria as well as to hypertension, DM, smoking, and job type.

Conclusions Chronic kidney disease was found in $16 \%$ of middle-aged workers with an equal prevalence in both sexes, while high-risk CKD was found mostly in men, of whom $3.3 \%$ were aged 55-64 years. Obesity, hypertension, DM, smoking and some job types were related to the development and progression of CKD.

Keywords Kidney disease $\cdot$ Proteinuria $\cdot$ Glomerular filtration rate $\cdot$ Risk factor $\cdot$ Health screening

\section{Introduction}

The concept of chronic kidney disease (CKD) characterized by clinical signs of renal damage, such as proteinuria and/or reduced glomerular filtration rate (GFR), was advocated by the National Kidney Foundation in the USA in 2002 [1] and endorsed by an international organization of the Kidney Disease: Improving Global Outcomes (KDIGO) [2] in the belief that the development of renal failure [end-stage kidney disease (ESKD)] can be prevented or delayed by the early detection and treatment of CKD. Since then, large numbers of CKD patients have been recognized all over the world [3, 4]. In Japan, the number of CKD patients is estimated to be 13.3 million 
(one in eight adults) by the Japanese Society of Nephrology (JSN) [5, 6]. CKD is, therefore, quite a common disease.

The significance of CKD as a common health problem has also been recognized not only with regard to its progression to ESKD but also to the high occurrence of associated cardiovascular disease (CVD) [7]. Mainly based on the strong association between proteinuria/albuminuria and the occurrence of CVD in CKD patients [8], KDIGO proposed new criteria of CKD severity in which great importance was attached to the presence of albuminuria [9], which presented a new paradigm of the significance of CKD as a public health issue. The Japanese version of the new criteria, mentioning proteinuria as well as albuminuria, was published by JSN in 2012 [6]. However, the impact of CKD on the health of working populations in Japan has not yet been well evaluated, in part because the measurement of serum creatinine $(\mathrm{Cr})$ concentrations is not mandated in the health check-ups conducted in workplaces.

Against this background, our aim was to clarify-at least in part-the impact of CKD on the health of the working population in Japan by determining the distribution of CKD severity and identifying possible contributing factors to its development and progression in middle-aged male and female workers/employees based on a 6-year retrospective longitudinal observational study.

\section{Subjects and methods}

\section{Selection of the subjects}

The subjects were selected from 4,004 male and 2,887 female workers/employees who were aged 35-64 years in 2009 and who had their serum $\mathrm{Cr}$ measured in the health check-ups carried out by an occupational health service organization located in Ishikawa prefecture, Japan, in both 2003 and 2009. Forty male and 189 female workers were excluded from the study due to a lack of critical data, mainly body weight or urinalysis data, resulting in 3,964 men and 2,698 women being selected as study subjects.

As described in our previous report [10], serum $\mathrm{Cr}$ concentrations had been measured in a total of 20,782 men and women working for 447 various enterprises during health check-ups carried out by the occupational health service organization in 2003. Many of the these individuals who were $<40$ years of age in 2003 did not take part in subsequent 6-year health check-ups because of the legally allowed exemption from blood biochemical testing for young workers. In comparison, nearly $70 \%$ of those aged $\geq 40$ years, namely, the age group most liable to CKD [11, 12] did participate in the health check-ups during the 6-year period.
Data collection

The subjects were asked to refrain from smoking for $\geq 30$ min prior to the health check-up. Height and weight were measured with jacket and shoes removed, and $0.5 \mathrm{~kg}$ was subtracted in April to September and $1.0 \mathrm{~kg}$ in October to March for the net body weight measurement. Body mass index (BMI) was calculated as the net body weight $(\mathrm{kg}) /$ height $(\mathrm{m})^{2}$. Blood pressure (BP) was measured with an automatic manometer (UM-15P; Parama-Tech Co., Fukuoka, Japan) with the subject in the sitting position on a chair after a $\geq 5$-min rest according to the guidelines of the Japanese Society of Hypertension [13]. Urine samples collected in the morning were analyzed immediately for protein concentration semi-quantitatively using a dipstick of Uro-paper III (Eikenkagaku Co., Tokyo, Japan).

Fasting venous blood samples were cooled on ice immediately after collection and conveyed to a laboratory for analyses within $4 \mathrm{~h}$. Hemoglobin A1c level (\%) in blood was first measured by the previous standard methods proposed by the Japan Diabetes Society using an automatic analyzer (model HLC-723G8; Tosoh Co., Tokyo, Japan) and then estimated as a National Glycohemoglobin Standardization Program equivalent value [14]. Plasma samples were analyzed for glucose concentration (FPG) using an automatic analyzer (model GA1170; Arkray Inc, Kyoto, Japan). Serum samples were analyzed for lipid concentrations, including total cholesterol (Tchol), low-density lipoprotein cholesterol (LDLc), high-density lipoprotein cholesterol (HDLc) and triglycerides (TG) using an automatic analyzer (model HITACHI-7700; Hitachi High-Technology Co., Tokyo, Japan). Serum Cr concentration was also measured by the automatic analyzer with an enzyme assay kit (N-Assay L CRE-K; Nittobo Medical Co., Tokyo, Japan).

Obesity was defined as "mild" when the BMI ranged from 25.0 to 29.9 and "marked" when it was $\geq 30.0$ [15]. Hypertension was defined as being present when the subject was being treated with antihypertensive agents and/or BP measured in the health check-ups was $\geq 140 / 90 \mathrm{mmHg}$ [13]. Diabetes mellitus (DM) was defined as present when the subject was being treated with hypoglycemic agents and/or had a FPG of $\geq 126 \mathrm{mg} / \mathrm{dL}$ or HbA1c of $\geq 6.5 \%$ (NGSP). Subjects were defined as having hypercholesterolemia (hChol) when they showed a Tchol of $\geq 220 \mathrm{mg} / \mathrm{dL}$ or LDLc of $\geq 140 \mathrm{mg} / \mathrm{dL}$, as hypo-HDL-cholesterolemia (lHDLc) when they had a HDLc of $<40 \mathrm{mg} / \mathrm{dL}$, and as hypertriglyceridemia (hTG) when they had a TG of $\geq 150 \mathrm{mg} / \mathrm{dL}$ in serum. Medications for dyslipidemia were not adopted in the definitions because of the vagueness of the subjects' answers.

Data on cigarette and usual alcohol consumption were obtained by interview by experienced nurses as mentioned in our previous articles [12, 16]. Smoking habit was 
classified into lifelong non-smoker, ex-smoker, and current smoker consuming up to one pack of cigarettes per day and those consuming more. The subjects were classified into non-drinker and drinkers consuming up to $29 \mathrm{~mL}$ of ethanol per day, $30-59 \mathrm{~mL}$ per day, or $\geq 60 \mathrm{~mL}$ per day. The classification of occupation was also the same as that described in our previous report [10], namely, clerk, manager/professional, sales/service, operator/driver, and "miscellaneous" jobs including security guards, farmers, and "unclassifiable" jobs. The subjects in the unclassifiable job category were surmised to be engaged mostly in some kinds of housekeeping work in private homes or various facilities judging from the names of their places of employment. Those classifications were also supposed to roughly reflect the degree of sedentariness at work.

\section{Determinations of CKD severity}

Chronic kidney disease and its severity were defined by the levels of GFR and proteinuria illustrated in the new JSN criteria [6]. GFR was estimated (eGFR) from serum Cr using the equation proposed by JSN [17], and the levels of eGFR (G) were classified into G1 $\left(\geq 90 \mathrm{~mL} / \mathrm{min} / 1.73 \mathrm{~m}^{2}\right), \mathrm{G} 2$ $\left(60-89 \mathrm{~mL} / \mathrm{min} / 1.73 \mathrm{~m}^{2}\right), \mathrm{G} 3 \mathrm{a} \quad\left(45-59 \mathrm{~mL} / \mathrm{min} / 1.73 \mathrm{~m}^{2}\right)$ G3b (30-44 mL/min/1.73 $\left.\mathrm{m}^{2}\right)$, G4 (15-29 mL/min/ $\left.1.73 \mathrm{~m}^{2}\right)$, and $\mathrm{G} 5\left(<15 \mathrm{~mL} / \mathrm{min} / 1.73 \mathrm{~m}^{2}\right)$. The amount of 24-h albumin or protein excretion in urine, which is required in the new JSN criteria, could not be determined by a dipstick measurement in spot urine samples collected in the health check-ups. In our study, therefore, dipstick proteinuria [(-) or $( \pm)$ ] measurements were tentatively assumed to correspond to the A1 (normal), A2 (dipstick 1+; mild proteinuria, and A3 (dipstick $\geq 2+$; marked proteinuria) categories, which are the same as the divisions adopted in a previous study conducted by JSN on Japanese adults receiving specific health check-ups for detecting the metabolic syndrome [18]. The severity of CKD was defined by the matrix of eGFR and proteinuria levels as follows: (1) "free of CKD" when the eGFR level was G1 or G2 without proteinuria; (2) "mild CKD" when the eGFR level was G1 or G2 with mild proteinuria, or G3a without proteinuria; (3) "moderate CKD" when the eGFR level was G1 or G2 with marked proteinuria, or G3a with mild proteinuria, or G3b without proteinuria; (4) "severe CKD" when the eGFR level was G3a with marked proteinuria, or G3b with any level of proteinuria, or G4 or G5 regardless of proteinuria. Data on the cause of kidney damage, which is also required in the new JSN criteria, were not available in our study cohort.

Statistical analyses

The distributions of proteinuria, eGFR levels, and CKD severity in the male and female workers divided by age groups in 2009 were determined. Incidences of proteinuria, total CKD, and moderate or severe CKD during the 6-year period between 2003 and 2009 were documented in those subjects who were free of those CKD signs in 2003 in relation to their basic characteristics, such as sex, age, BMI levels, presence of hypertension, DM and dyslipidemia, cigarette and alcohol consumption, occupation, and preceding CKD signs of reduced eGFR and/or proteinuria if present. The associations between signs of CKD signs and patient characteristics were tested for their statistical significance by univariate and multivariate logistic regression analyses. A $p$ value of $<0.05$ was considered to be statistically significant in all analyses.

Written informed consent was obtained from all subjects participating in the health check-ups by the occupational health service organization regarding the use of data collected in the health check-ups for academic purpose in anonymous forms. Our study was designed to analyze the data anonymized in an unlinkable fashion provided by the occupational health service organization and was approved by the ethics committee of Kanazawa Medical University.

\section{Results}

The mean (standard deviation) age of the male and female subjects in 2009 was 49.4 (7.8) and 50.2 (7.2) years, respectively, and the mean eGFR values were 71.0 (11.3) and 71.4 (11.6) $\mathrm{mL} / \mathrm{min} / 1.73 \mathrm{~m}^{2}$, respectively. The distributions of proteinuria, eGFR levels, and CKD severity in the men and women in 2009 by age groups are shown in Table 1. Proteinuria was found in $2.9 \%$ of the 3,964 men who participated in the study and in $1.1 \%$ of the 2,698 females who participated, including marked proteinuria $(\geq 2+)$ in $39 \%(1.0 \%)$ and $3 \%(0.1 \%)$ of the men and women, respectively. The prevalence of proteinuria increased with advancing age in the male subjects, but this trend was obscure in the female subjects.

A reduced eGFR of $<60 \mathrm{~mL} / \mathrm{min} / 1.73 \mathrm{~m}^{2}$ was detected in $14.1 \%$ of the men and $15.5 \%$ of the women; more specifically, $6 \%$ of the subjects aged 35-44 years, $15 \%$ of those aged 45-54 years, and $22 \%$ of those aged $55-64$ years had an eGFR of $<60 \mathrm{~mL} / \mathrm{min} / 1.73 \mathrm{~m}^{2}$, with a similar distribution in both sexes. A severely reduced eGFR of $<45 \mathrm{~mL} / \mathrm{min} / 1.73 \mathrm{~m}^{2}$ (G3b, G4 and G5) was limited to $27 \%(0.7 \%)$ of the men and $5 \%(0.2 \%)$ of the women, but increased conspicuously with advancing age to a prevalence of $4 \%(0.3 \%)$ and $9 \%(0.6 \%)$ of the men aged 35-44 and 45-54 years, respectively, and to $16 \%$ $(1.3 \%)$ and $5 \%(0.6 \%)$ of the men and women, respectively aged 55-64 years. Total CKD was found in 16.0 and $16.1 \%$ of the total cohort of male and female subjects, respectively. Moderate or severe CKD was more 
Table 1 Prevalence of proteinuria, estimated glomerular filtration rates, and chronic kidney disease severity in middle-aged male and female Japanese workers

\begin{tabular}{|c|c|c|c|c|c|c|c|c|}
\hline \multirow[t]{2}{*}{ Chronic kidney disease signs } & \multicolumn{2}{|l|}{$35-44$ years } & \multicolumn{2}{|l|}{$45-54$ years } & \multicolumn{2}{|l|}{$55-64$ years } & \multicolumn{2}{|l|}{ Total } \\
\hline & $\begin{array}{l}\text { Male } \\
(n=1,204)\end{array}$ & $\begin{array}{l}\text { Female } \\
(n=630)\end{array}$ & $\begin{array}{l}\text { Male } \\
(n=1,559)\end{array}$ & $\begin{array}{l}\text { Female } \\
(n=1,232)\end{array}$ & $\begin{array}{l}\text { Male } \\
(n=1,201)\end{array}$ & $\begin{array}{l}\text { Female } \\
(n=836)\end{array}$ & $\begin{array}{l}\text { Male } \\
(n=3,964)\end{array}$ & $\begin{array}{l}\text { Female } \\
(n=2,698)\end{array}$ \\
\hline \multicolumn{9}{|c|}{ Proteinuria (dipstick measurement) ${ }^{\mathrm{a}}$} \\
\hline $1+$ & 1.7 & 0.8 & 1.6 & 1.2 & 2.3 & 0.7 & 1.9 & 1.0 \\
\hline$\geq 2+$ & 0.6 & 0.0 & 0.9 & 0.2 & 1.5 & 0.1 & 1.0 & 0.1 \\
\hline \multicolumn{9}{|l|}{$\mathrm{eGFR}\left(\mathrm{mL} / \mathrm{min} / 1.73 \mathrm{~m}^{2}\right)^{\mathrm{b}}$} \\
\hline G1: $\geq 90$ & 8.2 & 13.8 & 3.4 & 5.5 & 3.6 & 2.4 & 4.9 & 6.5 \\
\hline G2: $60-89$ & 85.7 & 80.2 & 82.3 & 79.0 & 74.2 & 75.0 & 80.9 & 78.0 \\
\hline G3a: 45-59 & 5.7 & 6.0 & 13.8 & 15.5 & 21.0 & 22.0 & 13.5 & 15.3 \\
\hline G3b: $30-44$ & 0.1 & 0.0 & 0.4 & 0.0 & 1.0 & 0.5 & 0.5 & 0.1 \\
\hline G4: 15-29 & 0.0 & 0.0 & 0.1 & 0.0 & 0.1 & 0.1 & 0.1 & $<0.1$ \\
\hline G5: $\leq 14$ & 0.2 & 0.0 & 0.1 & 0.0 & 0.2 & 0.0 & 0.2 & 0.0 \\
\hline \multicolumn{9}{|c|}{ CKD severity $\left(\mathrm{mL} / \mathrm{min} / 1.73 \mathrm{~m}^{2}\right)^{\mathrm{b}}$} \\
\hline Mild & 7.0 & 6.5 & 14.0 & 15.5 & 21.0 & 22.2 & 14.0 & 15.5 \\
\hline Moderate & 0.6 & 0.2 & 1.3 & 0.6 & 2.3 & 0.6 & 1.4 & 0.5 \\
\hline Severe & 0.3 & 0.0 & 0.5 & 0.1 & 1.0 & 0.2 & 0.6 & 0.1 \\
\hline
\end{tabular}

eGFR estimated glomerular filtration rate based on serum creatinine $(\mathrm{Cr})$ level, $C K D$ chronic kidney disease

Data are presented as the prevalence $(\%)$ of each variable

${ }^{a}$ Dipstick measurement: $1+$, mild proteinuria (A2), $\geq 2+$, marked proteinuria (A3) categories

${ }^{b}$ For the definitions/units of eGFR levels and CKD severity, see text (Determinations of CKD severity)

commonly found in the male subjects than in the female ones: $79(2.0 \%)$ of the total male cohort [11 $(0.9 \%)$ of those aged 35-44 years, $28(1.8 \%)$ of those aged $45-54$ years, $40(3.3 \%)$ of those aged 55-64 years] versus $17(0.6 \%)$ of the total female cohort [1 $(0.2 \%)$ of those aged 35-44 years, $9(0.7 \%)$ of those $45-54$ years, 7 $(0.8 \%)$ of those 55-64 years].

Table 2 shows the basic characteristics of all study subjects in 2003. The prevalence of all the health conditions associated with hypertension, DM, and dyslipidemia increased with advancing age, with the exception of lHDLc, and were more prevalent in the male subjects than in the female ones, with the exception of an extremely high prevalence of hChol in females aged 55-64 years. The number of current smokers among the male subjects decreased with advancing age, while that of heavy smokers increased. Current smokers accounted for $10 \%$ of the female subjects, of whom $\leq 0.5 \%$ were heavy smokers in all age groups. The number of subjects who consumed ethanol at a level of of $\geq 30 \mathrm{~mL}$ per day increased with advancing age in the men but accounted for fewer $<5 \%$ of the women in all age groups. Operator/driver and manager/ professional were the most common job classifications among the male subjects, while most common occupations of the female subjects were as clerks (women aged 35-54 years) and sales/service workers (women aged
55-64 years). In the "miscellaneous" job category, 45 men and three women worked as security guards, 12 men and five women were farmers, and seven men and 66 women could not be classified (mostly some housekeeping work).

Table 3 shows the results of the univariate and multivariate logistic regression analyses on the association of the development of proteinuria during a 6-year period with the basic characteristics in the subjects who did not show proteinuria in 2003. The table shows odds ratios with the $95 \%$ confidence interval for each category of the characteristics in comparison with the reference category. The univariate analyses showed that the incidence of proteinuria was significantly lower in the female subjects than in the male ones and that obesity, presence of hypertension, DM, and dyslipidemias of hChol, hTG, and lHDLc as well as current smoking were strongly related to a high incidence of proteinuria $(p<0.01)$. The job type of sales/ service showed a weak but significant relation to a high incidence of proteinuria $(p<0.05)$. Preceding slightly reduced eGFR $\left(60-89 \mathrm{~mL} / \mathrm{min} / 1.73 \mathrm{~m}^{2}\right)$ was not significantly related to proteinuria. Table 3 also shows the results of a multivariate logistic regression analysis that included all of the characteristics listed in the table as independent variables. Sex was not independently related to a high incidence of proteinuria nor were dyslipidemias of hChol, hTG, and lHDLc. Marked obesity, presence of 
Table 2 Distribution of basic characteristics possibly related to the development of chronic kidney disease the male and female subjects observed in 2003

\begin{tabular}{|c|c|c|c|c|c|c|c|c|}
\hline \multirow[t]{2}{*}{ Characteristics } & \multicolumn{2}{|c|}{$35-44$ years $^{\mathrm{a}}$} & \multicolumn{2}{|c|}{$45-54$ years $^{\mathrm{a}}$} & \multicolumn{2}{|l|}{$55-64$ years $^{\mathrm{a}}$} & \multicolumn{2}{|l|}{ Total } \\
\hline & $\begin{array}{l}\text { Male } \\
(n=1,204)\end{array}$ & $\begin{array}{l}\text { Female } \\
(n=630)\end{array}$ & $\begin{array}{l}\text { Male } \\
(n=1,559)\end{array}$ & $\begin{array}{l}\text { Female } \\
(n=1,232)\end{array}$ & $\begin{array}{l}\text { Male } \\
(n=1,201)\end{array}$ & $\begin{array}{l}\text { Female } \\
(n=836)\end{array}$ & $\begin{array}{l}\text { Male } \\
(n=3,964)\end{array}$ & $\begin{array}{l}\text { Female } \\
(n=2,698)\end{array}$ \\
\hline \multicolumn{9}{|c|}{ Obesity $\left(\mathrm{BMI}, \mathrm{mL} / \mathrm{min} / 1.73 \mathrm{~m}^{2}\right)^{\mathrm{b}}$} \\
\hline Mild & 19.4 & 7.1 & 25.9 & 14.0 & 27.8 & 16.5 & 24.5 & 13.2 \\
\hline Marked & 4.7 & 1.4 & 3.2 & 2.3 & 1.7 & 2.0 & 3.2 & 2.0 \\
\hline \multicolumn{9}{|l|}{ Health conditions ${ }^{\mathrm{b}}$} \\
\hline Hypertension & 13.2 & 2.7 & 25.3 & 9.7 & 34.2 & 22.8 & 24.3 & 12.2 \\
\hline DM & 1.8 & 0.5 & 5.3 & 1.6 & 11.1 & 3.1 & 6.0 & 1.8 \\
\hline hChol & 19.1 & 10.0 & 30.8 & 21.3 & 30.7 & 42.5 & 27.2 & 25.2 \\
\hline hTG & 17.8 & 2.4 & 23.9 & 3.2 & 20.1 & 5.9 & 20.9 & 3.9 \\
\hline 1HDLc & 9.1 & 1.9 & 7.9 & 1.9 & 9.5 & 1.4 & 8.8 & 1.7 \\
\hline \multicolumn{9}{|l|}{ Cigarette smoking } \\
\hline Ex-smoker & 14.8 & 2.5 & 26.0 & 1.5 & 28.6 & 2.0 & 23.4 & 1.9 \\
\hline Smoke up to $1 \mathrm{pack} /$ day & 44.0 & 9.5 & 35.1 & 8.8 & 31.1 & 9.7 & 36.6 & 9.2 \\
\hline Smoke more & 13.3 & 0.2 & 17.1 & 0.4 & 20.6 & 0.5 & 17.0 & 0.4 \\
\hline \multicolumn{9}{|l|}{ Alcohol consumption } \\
\hline Drink up to $29 \mathrm{~mL} /$ day & 40.5 & 23.8 & 33.2 & 24.3 & 31.6 & 21.8 & 34.9 & 23.4 \\
\hline $30-59 \mathrm{~mL} /$ day & 15.0 & 3.2 & 25.0 & 3.3 & 24.4 & 3.1 & 21.8 & 3.2 \\
\hline $60 \mathrm{~mL} /$ day or more & 8.5 & 1.3 & 15.2 & 0.9 & 21.1 & 1.2 & 14.9 & 0.4 \\
\hline \multicolumn{9}{|l|}{ Occupation } \\
\hline Clerk & 23.2 & 51.4 & 29.1 & 38.0 & 20.3 & 24.6 & 24.6 & 37.0 \\
\hline Manager/professional & 23.5 & 19.2 & 30.5 & 24.4 & 30.8 & 17.7 & 28.5 & 21.1 \\
\hline Sales/service & 21.9 & 16.0 & 14.0 & 24.3 & 11.1 & 36.6 & 15.5 & 26.2 \\
\hline Operator/driver & 29.5 & 9.8 & 25.4 & 11.2 & 35.6 & 17.9 & 29.7 & 13.0 \\
\hline Miscellaneous & 1.8 & 3.5 & 1.0 & 2.1 & 2.2 & 3.1 & 1.6 & 2.7 \\
\hline
\end{tabular}

DM Diabetes mellitus, $h C h o l$ hypercholesterolemia [a Tchol (total cholesterol of $\geq 220 \mathrm{mg} / \mathrm{dL}$ ], $h T G$ hypertriglyceridemia, $i H D L c$ hypo-HDLcholesterolemia

Data are presented as the prevalence $(\%)$

a Subjects who were aged 35-44, 45-54, and 55-64 years in 2009 were aged 29-38, 39-48, and 49-58 years, respectively, in 2003

${ }^{\mathrm{b}}$ For the definitions of the health conditions, refer to section Data collection

hypertension and DM, and current smoking showed strong independent associations with proteinuria. The "miscellaneous" job type showed a significant positive association with a high incidence of proteinuria, while mild alcohol consumption showed a significant negative association with it, suggesting that some degree of alcohol consumption has a protective effect against the development of proteinuria.

Although the results are not shown in tables, we conducted similar analyses on the association between the development of total CKD (including any type of severity) with the basic characteristics of the subjects. Univariate analyses showed that the development of total CKD was not related to sex, but strongly related to increases in age and BMI, presence of hypertension, hChol, and hTG, and the "miscellaneous" job category as well as by preceding slightly reduced eGFR (G2: $\left.60-89 \mathrm{~mL} / \mathrm{min} / 1.73 \mathrm{~m}^{2}\right)$. On the other hand, DM, lHDLc, smoking, and alcohol consumption did not show significant associations with total CKD. The results of a multivariate analysis showed a significant independent association of increases in age and BMI, hTG, "miscellaneous" job category, and slightly reduced eGFR with the development of total CKD. Alcohol consumption of any dose showed a protective association with total CKD.

Table 4 shows the results of univariate and multivariate logistic regression analyses on the factors related to the development of moderate or severe CKD. The subjects included those showing mild CKD in 2003. In the univariate analyses, female subjects showed a significantly lower incidence of moderate or severe CKD than the male ones. Increases in age, especially in the oldest age group of 55-64 years, presence of hypertension and DM, current smoking, and preceding mild CKD signs of reduced eGFR 
Table 3 Results of univariate and multivariate logistic regression analyses on the association of basic subject characteristics with the development of proteinuria

\begin{tabular}{|c|c|c|c|c|c|c|}
\hline \multirow[t]{2}{*}{ Characteristics } & \multicolumn{3}{|c|}{ Univariate } & \multicolumn{3}{|c|}{ Multivariate $^{\mathrm{a}}$} \\
\hline & OR & $95 \% \mathrm{CI}$ & $p$ & OR & $95 \% \mathrm{CI}$ & $p$ \\
\hline Female:male & 0.47 & $0.29-0.74$ & 0.001 & 0.95 & $0.48-1.87$ & 0.875 \\
\hline \multicolumn{7}{|c|}{ Age $^{\mathrm{b}}:$ 35-44 years (Reference) } \\
\hline $45-54$ & 0.99 & $0.59-1.65$ & 0.960 & 0.90 & $0.52-1.56$ & 0.709 \\
\hline $55-64$ & 1.43 & $0.86-2.38$ & 0.174 & 1.10 & $0.62-1.95$ & 0.751 \\
\hline \multicolumn{7}{|c|}{ Body mass index: $18.5-24.9 \mathrm{~kg} / \mathrm{m}^{2}$ (Reference) } \\
\hline$\leq 18.4$ & 1.13 & $0.45-2.85$ & 0.800 & 1.55 & $0.60-4.00$ & 0.366 \\
\hline $25.0-29.9$ & 2.30 & $1.45-3.64$ & $<0.001$ & 1.51 & $0.92-2.47$ & 0.103 \\
\hline$\geq 30.0$ & 9.89 & $5.49-17.8$ & $<0.001$ & 4.52 & $2.31-8.84$ & $<0.001$ \\
\hline \multicolumn{7}{|c|}{ Health conditions (none: Reference) ${ }^{\mathrm{c}}$} \\
\hline Hypertension (+) & 3.57 & $2.39-5.34$ & $<0.001$ & 2.49 & $1.59-3.91$ & $<0.001$ \\
\hline $\mathrm{DM}(+)$ & 6.70 & $4.07-11.0$ & $<0.001$ & 3.51 & $2.02-6.08$ & $<0.001$ \\
\hline hChol (+) & 1.74 & $1.16-2.63$ & 0.008 & 1.23 & $0.78-1.92$ & 0.372 \\
\hline hTG $(+)$ & 2.39 & $1.52-3.74$ & $<0.001$ & 1.25 & $0.75-2.08$ & 0.391 \\
\hline $\mathrm{iHDLc}(+)$ & 2.49 & $1.38-4.51$ & 0.003 & 1.30 & $0.67-2.51$ & 0.439 \\
\hline \multicolumn{7}{|c|}{ Smoking: none (Reference) } \\
\hline Ex-smoker & 1.85 & $0.96-3.55$ & 0.066 & 1.77 & $0.80-3.94$ & 0.160 \\
\hline Up to 1 pack/day & 2.40 & $1.43-4.04$ & 0.001 & 2.61 & $1.36-5.02$ & 0.004 \\
\hline Smoke more & 5.11 & $2.96-8.82$ & $<0.001$ & 4.52 & $2.17-9.41$ & $<0.001$ \\
\hline \multicolumn{7}{|l|}{ Alcohol: none (Reference) } \\
\hline$\leq 29 \mathrm{~mL} /$ day & 0.80 & $0.49-1.32$ & 0.384 & 0.59 & $0.34-0.99$ & 0.048 \\
\hline $30-59 \mathrm{~mL} /$ day & 1.05 & $0.59-1.89$ & 0.864 & 0.62 & $0.32-1.19$ & 0.153 \\
\hline$\geq 60 \mathrm{~mL} /$ day & 1.52 & $0.83-2.78$ & 0.178 & 0.67 & $0.34-1.35$ & 0.263 \\
\hline \multicolumn{7}{|c|}{ Occupation $^{c}$ : clerk (Reference) } \\
\hline Manager/Professional & 1.58 & $0.89-2.84$ & 0.122 & 1.49 & $0.82-2.71$ & 0.195 \\
\hline Sales/service & 1.89 & $1.05-3.42$ & 0.035 & 1.57 & $0.85-2.91$ & 0.152 \\
\hline Operator/driver & 1.48 & $0.81-2.71$ & 0.200 & 1.21 & $0.65-2.28$ & 0.547 \\
\hline Miscellaneous & 2.85 & $0.96-8.45$ & 0.059 & 3.40 & $1.11-10.4$ & 0.032 \\
\hline Reduced eGFR ${ }^{\mathrm{d}}(+)$ & 0.79 & $0.51-1.21$ & 0.276 & 0.93 & $0.58-1.48$ & 0.757 \\
\hline
\end{tabular}

OR odds ratio, $95 \%$ CI $95 \%$ confidence interval

a All the characteristics were included in the analysis as independent variables

b Age in 2009

${ }^{c}$ For the definitions of the health conditions, refer to section Data collection

d eGFR of $60-89 \mathrm{~mL} / \mathrm{min} / 1.73 \mathrm{~m}^{2}$

$\left(45-59 \mathrm{~mL} / \mathrm{min} / 1.73 \mathrm{~m}^{2}\right)$ and dipstick proteinuria (1+) were strongly related to a high incidence of moderate or severe CKD. The "miscellaneous" job category also showed a significant relation to a high incidence of moderate or severe CKD. The results of a multivariate analysis showed that hypertension, DM, and the "miscellaneous" job category were strongly related to the development of moderate or severe CKD. Extremely strong associations were found with the preceding CKD signs of reduced eGFR and proteinuria. In addition, the oldest age group of 55-64 years and current smoking showed significant positive associations with the development of moderate or severe CKD while the consumption of $\geq 60 \mathrm{~mL}$ alcohol per day showed a significant negative association; none of the dyslipidemias showed a significant association with it.

\section{Discussion}

The distribution of CKD

The subjects participating in our study accounted for fewer than $40 \%$ of the total 20,782 workers who had been examined for serum $\mathrm{Cr}$ in the health check-ups in 2003. However, nearly $70 \%$ of the working individuals in the age category $\geq 40$ years were successfully followed up 
Table 4 Results of univariate and multivariate logistic regression analyses on the association of basic characteristics with the development of moderate or severe chronic kidney disease

\begin{tabular}{|c|c|c|c|c|c|c|}
\hline \multirow[t]{2}{*}{ Characteristics } & \multicolumn{3}{|c|}{ Univariate } & \multicolumn{3}{|c|}{ Multivariate $^{\mathrm{a}}$} \\
\hline & OR & $95 \% \mathrm{CI}$ & $p$ & OR & $95 \% \mathrm{CI}$ & $p$ \\
\hline Female:male & 0.37 & $0.21-0.65$ & 0.001 & 0.56 & $0.25-1.23$ & 0.149 \\
\hline \multicolumn{7}{|c|}{ Age $^{\text {b }}: 35-44$ years (Reference) } \\
\hline $45-54$ & 2.13 & $1.01-4.52$ & 0.048 & 1.97 & $0.88-4.42$ & 0.101 \\
\hline $55-64$ & 3.66 & $1.76-7.62$ & 0.001 & 2.44 & $1.07-5.57$ & 0.034 \\
\hline \multicolumn{7}{|c|}{ Body mass index $18.5-24.9 \mathrm{~kg} / \mathrm{m}^{2}$ (Reference) } \\
\hline$\leq 8.4$ & 0.73 & $0.23-2.34$ & 0.592 & 1.21 & $0.35-4.13$ & 0.763 \\
\hline $25.0-29.9$ & 1.68 & $1.00-2.83$ & 0.052 & 0.97 & $0.54-1.73$ & 0.909 \\
\hline$\geq 30.0$ & 2.96 & $1.16-7.54$ & 0.023 & 0.77 & $0.24-2.49$ & 0.660 \\
\hline \multicolumn{7}{|c|}{ Health conditions (none: Reference) ${ }^{\mathrm{c}}$} \\
\hline Hypertension $(+)$ & 4.30 & $2.72-6.82$ & $<0.001$ & 3.01 & $1.78-5.11$ & $<0.001$ \\
\hline $\mathrm{DM}(+)$ & 7.08 & $4.06-12.3$ & $<0.001$ & 3.69 & $1.94-7.03$ & $<0.001$ \\
\hline hChol (+) & 1.43 & $0.88-2.33$ & 0.146 & 0.95 & $0.56-1.63$ & 0.852 \\
\hline hTG $(+)$ & 1.72 & $0.99-3.01$ & 0.056 & 1.03 & $0.55-1.95$ & 0.920 \\
\hline 1HDLc $(+)$ & 1.17 & $0.47-2.91$ & 0.739 & 0.63 & $0.23-1.75$ & 0.380 \\
\hline \multicolumn{7}{|c|}{ Smoking: none (Reference) } \\
\hline Ex-smoker & 2.73 & $1.41-5.29$ & 0.003 & 1.67 & $0.72-3.86$ & 0.230 \\
\hline Up to $1 \mathrm{pack} / \mathrm{day}$ & 2.36 & $1.30-4.29$ & 0.005 & 2.58 & $1.21-5.49$ & 0.014 \\
\hline Smoke more & 3.45 & $1.73-6.86$ & $<0.001$ & 2.98 & $1.22-7.27$ & 0.016 \\
\hline \multicolumn{7}{|c|}{ Alcohol: none (Reference) } \\
\hline $\mathrm{Up}$ to $29 \mathrm{~mL} /$ day & 0.99 & $0.56-1.74$ & 0.962 & 0.55 & $0.29-1.03$ & 0.062 \\
\hline $30-59 \mathrm{~mL} /$ day & 1.47 & $0.78-2.78$ & 0.234 & 0.62 & $0.30-1.30$ & 0.209 \\
\hline $60 \mathrm{~mL} /$ day or more & 1.44 & $0.68-3.05$ & 0.336 & 0.40 & $0.16-0.96$ & 0.041 \\
\hline \multicolumn{7}{|c|}{ Occupation $^{\mathrm{d}}$ : clerk (Reference) } \\
\hline Manager/professional & 1.53 & $0.80-2.94$ & 0.202 & 1.25 & $0.62-2.52$ & 0.535 \\
\hline Sales/service & 1.60 & $0.81-3.18$ & 0.179 & 1.57 & $0.76-3.25$ & 0.228 \\
\hline Operator/driver & 1.30 & $0.65-2.60$ & 0.463 & 0.93 & $0.44-1.96$ & 0.842 \\
\hline Miscellaneous & 3.64 & $1.20-11.0$ & 0.022 & 5.89 & $1.84-18.7$ & 0.003 \\
\hline Reduced eGFR ${ }^{\mathrm{d}}(+)$ & 7.73 & $4.25-14.1$ & $<0.001$ & 9.39 & $4.80-18.4$ & $<0.001$ \\
\hline Proteinuria $(1+)$ & 33.0 & $17.2-63.3$ & $<0.001$ & 38.8 & $18.1-83.2$ & $<0.001$ \\
\hline
\end{tabular}

${ }^{a}$ All the characteristics were included in the analysis as independent variables

b Age in 2009

${ }^{c}$ For the definitions of the health conditions, refer to section Data collection

d eGFR of $45-59 \mathrm{~mL} / \mathrm{min} / 1.73 \mathrm{~m}^{2}$

until 2009. Both proteinuria [12] and CKD [11] are generally rare in young people and are detected mostly in people aged $\geq 40$ years who are thus thought to be more liable to develop CKD. Our results obtained in members of the working population aged 35-64 years can therefore be generalized with a certain validity to the middle-aged working population in Japan. The distribution of CKD in our subjects can be summarized as follows: (1) total CKD was present in $16 \%$ of the subjects at a similar prevalence in both sexes; (2) moderate or severe CKD associated with a high risk of CVD and ESKD [6,9] was found at a low prevalence but occurred approximately twofold more frequently in the male subjects than in the female ones and in $3.3 \%$ of the males aged 55-64 years. This high prevalence of high-risk CKD in the oldest male group is especially significant for occupational health management in Japan since the number of workers in that age group is increasing rapidly in workplaces.

To our knowledge, no comparable data have been made available regarding the distribution of CKD with its severity defined by the new JSN criteria except for data from an observational study on 332,174 participants in a 
specific health check-up for the metabolic syndrome [18]; in this study the subjects were aged 40-74 years, with women comprising $60 \%$ of the total. The mean age of the participants was 63.6 years and the mean eGFR was $75.0 \mathrm{~mL} / \mathrm{min} / 1.73 \mathrm{~m}^{2}$. The prevalence of proteinuria and of a reduced eGFR of $<60 \mathrm{~mL} / \mathrm{min} / 1.73 \mathrm{~m}^{2}$ was 5.4 and $14.2 \%$, respectively. Thus, the participants in that study showed a considerably higher mean eGFR and lower prevalence of reduced eGFR than those in our study who were on average aged 10 years more younger, and the former also showed proteinuria and high-risk CKD at rates as high as 5.4 and $3.7 \%$, respectively, being more than 3.8 and $3.3 \%$, respectively, higher than those in our oldest male subjects (aged 55-64 years). The reasons underlying these discordant findings are unclear, but they strongly suggest the need for further studies on the distribution of CKD severity in various populations since it may considerably differ among populations with different characteristics..

We noted that the prevalence of proteinuria in our subjects ( $2.9 \%$ of the men and $1.1 \%$ of the women) was much lower than expected. Proteinuria has been detected in $3.4-4.4 \%$ of the national working population in Japan during the last decade [19]. The low prevalence of proteinuria in our study subjects may have been, at least partly, caused by selecting for inclusion in the study those workers whose serum $\mathrm{Cr}$ had been measured in both 2003 and 2009. Many of the older workers likely dropped out due to having reached retirement age during the 6-year intervening period between health check-ups. In constrast, drop-outs among the younger workers can be surmised to have occurred more often among those in poor health, which would inevitably reduce the prevalence of any sign of ill-health, including proteinuria. Further, $50 \%$ of the ten male subjects who were ultimately excluded from the study because of a lack of urinalysis data showed an elevated serum $\mathrm{Cr}$ suggesting CKD, and three of these had levels as high as $\geq 8 \mathrm{mg} / \mathrm{dL}$, which is defined as ESKD. Owing to the low prevalence of proteinuria among our study cohort, our results may have somewhat understated the true prevalence of CKD in this population.

On the other hand, the low prevalence of proteinuria in our subjects might have been related to the low prevalence of obesity in this group [20-22]. There were fewer obese people with a BMI of $\geq 25$ in our study cohort than in the general Japanese population (4-5\% fewer in men and 2-3\% fewer in women) [23]. Other factors possibly contributing to the development of proteinuria or CKD, such as hypertension, DM, dyslipidemia, and cigarette and alcohol consumption, did not seem to differ appreciably from those in the general population in the national survey [23], although the same measurements and definitions were not applied in both studies. In any case, the figure of $16 \%$ for the prevalence of
CKD in our cohort of male and female workers aged 35-64 years, even though being somewhat understated, is generally in accordance with the figure of $13 \%$ estimated by JSN for Japanese adults aged $\geq 20$ years [11].

Factors contributing to the development and progression of $\mathrm{CKD}$

Contributing factors to the development and progression of CKD were analyzed first in a univariate analysis and then in a multivariate analysis. The development of proteinuria in our subjects was strongly related to marked obesity, hypertension, DM, and current smoking. Alcohol consumption, especially mild consumption, showed some protective effects against the development of proteinuria. These findings are in good accordance with those of our previous studies $[10,16]$. The development of total CKD was, however, related to increases in age and BMI and hTG, but not to hypertension, DM, or smoking, which also is in accordance with the findings related to the development of reduced eGFR observed in our previous study [10]. On the other hand, moderate or severe CKD, i.e., high-risk CKD, was related to hypertension, DM, and smoking as well as to preceding mild CKD signs, thereby showing that the factors contributing to the development of proteinuria and, therefore, CKD, contribute to the further progression of CKD.

Our results confirm that hypertension, DM, smoking, and obesity are strong factors contributing to the development and progression of CKD in our middle-aged workers, but there were no significant effects of dyslipidemia, except for a weak one of hTG on total CKD, on the development of proteinuria or CKD. However, dyslipidemia, including hTG [24] and hChol [25, 26], has been detected as a significant risk factor for the development of proteinuria and CKD in previous studies. Further, strict control of dyslipidemia would be beneficial in preventing CVD in CKD patients [27]. Therefore, the roles of dyslipidemia in the development and progression of CKD should be further investigated. The protective effect of alcohol consumption against the development of proteinuria and CKD may be related to the anti-atherogenic property of mild alcohol consumption [28].

Some kinds of job referred to as "miscellaneous" were related to the development and progression of CKD in our subjects. Those individuals categorized as being "miscellaneous" workers worked mainly as security guards and farmers (men) or in housekeeping tasks (females). Although not actually measured, guards, farmers, and housekeepers may be physically more active at work in comparison with those in other job types. Workers who are physically more active have been shown to be at a high risk for developing renal failure $[29,30]$. Also, their socioeconomic status may be lower; this would have affected the 
study results as health/healthcare disparities between social stratifications are present in CKD [31-33]. The exact features of the association between some job types and CKD observed in our study remain unclear, and further studies are required.

\section{Limitations of the study}

In addition to the possible understatement of the prevalence of CKD owing to the manner in which subjects were selected, there are a number of other limitations to our study. First, subjects were not entered into our study in a randomized fashion; rather, they were recruited from businesses/factories/commercial enterprises that could afford to have their employees measured for serum $\mathrm{Cr}$, which is not mandated in such health check-ups. Therefore, the subjects may have been of better socioeconomic status in comparison with the general working population in Japan and thus be in a better health condition as reflected by, for example, the lower prevalence of proteinuria and obesity. However, most of our subjects were recruited from small or medium-sized private businesses in a local area of Japan, and thus the socioeconomic status of the employees was not thought to be appreciably better than that of the general working population in Japan.

Second, there are limitations related to the outcome measurements. The measurement of proteinuria using a dipstick method has not been fully validated in relation to the measurement of 24-h albumin or protein excretion that is required in the new JSN criteria for CKD severity. The limited validity of the dipstick measurement is illustrated in the JSN guidebooks [6, 34]; for example, "mild" proteinuria of $0.15-0.49 \mathrm{~g} / \mathrm{day}$ or $\mathrm{g} / \mathrm{g}$ Cr corresponded to "normal (-)" to "marked proteinuria $(2+)$ " of the dipstick measurements, whereas $\geq 40 \%$ of urine samples showing dipstick "mild proteinuria $(1+)$ " actually had "marked" proteinuria of $\geq 0.5 \mathrm{~g} /$ day or $\mathrm{g} / \mathrm{g} \mathrm{Cr}$. Although it was not mentioned in our results, one-third of our subjects who had been defined as having mild CKD in 2003 were free of CKD in 2009, mostly due to the disappearance of proteinuria, which highlights the limited reproducibility of proteinuria as detected by dipstick in the health check-ups. Further, GFR estimated from serum $\mathrm{Cr}$ has not been fully validated in healthy populations, especially in those with an extremely low or high body weight. Furthermore, the single measurements of CKD signs in health check-up settings did not meet the clinical definition of CKD, which requires the persistence of the signs for $\geq 3$ months.

Third, in our study we did not analyze the effects of some factors possibly related to the development and progression of CKD. Gout or hyperuricemia has been shown to relate to the development and progression of renal dysfunction [35-37], although the effects may not be as strong as those of hypertension, DM, obesity, and smoking [38]. Occupational and environmental exposure to renal toxic substances, such as organic solvents [39, 40] and heavy metals like lead [41, 42] or cadmium [43, 44], was not evaluated in the present study. Cadmium may intervene between cigarette smoking and renal damage [45, 46]. Studies focusing on the relationship of extensive working conditions, including exposure to renal toxic substances, and socioeconomic status with the development and progression of CKD are required.

\section{Conclusions}

Chronic kidney disease was detected in $16 \%$ of middleaged Japanese workers/employees at an equal prevalence in both sexes. High-risk CKD for developing CVD and end-stage renal disease was found in $3.3 \%$ of the male subjects aged 55-64 years, which implies a significant impact of CKD on the rapidly aging working population in Japan. Associations between hypertension, DM, obesity, and smoking and the development of proteinuria and highrisk CKD highlights the importance of early detection of CKD in health check-ups and lifestyle modifications with adequate treatments for hypertension and DM, if present, for preventing the development and progression of CKD in working populations. However, this association remains to be confirmed by future interventional studies.

Acknowledgments This work was supported by KAKENHI, a Grant-in-Aid for Scientific Research (C), 2012-2012, from the Japan Society for the Promotion of Science (JSPS).

Conflict of interest The authors declare that they have no conflict of interest.

\section{References}

1. National Kidney Foundation. K/DOQI clinical practice guidelines for chronic kidney disease: evaluation, classification, and stratification. Am J Kidney Dis. 2002;39:S1-266.

2. Levey AS, Eckardt KU, Tsukamoto Y, Levin A, Coresh J, Rossert J, et al. Definition and classification of chronic kidney disease: a position statement from Kidney Disease: Improving Global Outcomes (KDIGO). Kidney Int. 2005;67:2089-100.

3. Hallan SI, Coresh J, Astor BC, Asberg A, Powe NR, Romundstad $\mathrm{S}$, et al. International comparison of the relationship of chronic kidney disease prevalence and ESRD risk. J Am Soc Nephrol. 2006;17:2275-84.

4. Imai E, Matsuo S. Chronic kidney disease in Asia. Lancet. 2008;371:2147-8.

5. Japanese Society of Nephrology. Clinical Practice Guidebook for Diagnosis and Treatment of Chronic Kidney Disease 2009. Tokyo: Tokyo-Igaku Co.; 2009 (In Japanese).

6. Japanese Society of Nephrology. Clinical practice guidebook for diagnosis and treatment of chronic kidney disease 2012. Tokyo: Tokyo-Igaku Co.; 2012 (in Japanese). 
7. Sarnak MJ, Levey AS, Schoolwerth AC, Coresh J, Culleton B, Hamm LL, et al. Kidney disease as a risk factor for development of cardiovascular disease: a statement from the American Heart Association Councils on Kidney in Cardiovascular Disease, High Blood Pressure Research, Clinical Cardiology, and Epidemiology and Prevention. Circulation. 2003;108:2154-69.

8. Matsushita K, van der Velde M, Astor BC, Woodward M, Levey AS, de Jong PE, et al. Association of estimated glomerular filtration rate and albuminuria with all-cause and cardiovascular mortality in general population cohorts: a collaborative metaanalysis. Lancet. 2010;375:2073-81.

9. Levey AS, de Jong PE, Coresh J, El Nahas M, Astor BC, Matsushita K, et al. The definition, classification, and prognosis of chronic kidney disease: a KDIGO Controversies Conference report. Kidney Int. 2011;80:17-28.

10. Noborisaka Y, Ishizaki M, Yamada Y, Honda R, Yokoyama H, Miyao $\mathrm{M}$, et al. The effects of continuing and discontinuing smoking on the development of chronic kidney disease (CKD) in the healthy middle-aged working population in Japan. Environ Health Prev Med. 2013;18:24-32.

11. Imai $\mathrm{E}$, Horio $\mathrm{M}$, Watanabe $\mathrm{T}$, Iseki $\mathrm{K}$, Yamagata $\mathrm{K}$, Hara $\mathrm{S}$, et al. Prevalence of chronic kidney disease in the Japanese general population. Clin Exp Nephrol. 2009;13:621-30.

12. Yamada $Y$, Noborisaka $Y$, Ishizaki M, Honda R, Tsuritani I, Yamada S. Association between cigarette consumption and proteinuria in healthy Japanese men and women from an occupational population. J Occup Health. 2004;46:365-73.

13. Ogihara T, Kikuchi K, Matsuoka H, Fujita T, Higaki J, Horiuchi M, et al. The Japanese Society of Hypertension Guidelines for the Management of Hypertension (JSH 2009). Hypertens Res. 2009;32:3-107.

14. Kashiwagi A, Kasuga M, Araki E, Oka Y, Hanafusa T, Ito H, et al. International clinical harmonization of glycated hemoglobin in Japan: from Japan Diabetes Society to National Glychohemoglobin Standardization Program values. Diabetol Int. 2012;3:8-10.

15. Japan Society for the Study of Obesity. The criteria for diagnosis of obesity. JJSSO. 2011;17:1-2. (in Japanese).

16. Noborisaka Y, Ishizaki M, Nakata M, Yamada Y, Honda R, Yokoyama $\mathrm{H}$, et al. Cigarette smoking, proteinuria, and renal function in middle-aged Japanese men from an occupational population. Environ Health Prev Med. 2012;17:147-56.

17. Matsuo S, Imai E, Horio M, Yasuda Y, Tomita K, Nitta K, et al. Revised equations for estimated GFR from serum creatinine in Japan. Am J Kidney Dis. 2009;53:982-92.

18. Iseki K, Asahi K, Moriyama T, Yamagata K, Tsuruya K, Yoshida $\mathrm{H}$, et al. Risk factor profiles based on estimated glomerular filtration rate and dipstick proteinuria among participants of the Specific Health Check and Guidance System in Japan 2008. Clin Exp Nephrol. 2012;16:244-9.

19. Japan Industrial Safety \& Health Association. General guidebook on industrial health. Tokyo: Japan Industrial Safety \& Health Association; 2011. p. 34. (in Japanese).

20. Fujibayashi K, Fukuda H, Yokokawa H, Haniu T, Oka F, Ooike $\mathrm{M}$, et al. Associations between healthy lifestyle behaviors and proteinuria and the estimated glomerular filtration rate (eGFR). J Atheroscler Thromb. 2012;19:932-40.

21. Stengel B, Tarver-Carr ME, Powe NR, Eberhardt MS, Brancati FL. Lifestyle factors, obesity and the risk of chronic kidney disease. Epidemiology. 2003;14:479-87.

22. Yamagata K, Ishida K, Sairenchi T, Takahashi H, Ohba S, Shiigai $\mathrm{T}$, et al. Risk factors for chronic kidney disease in a communitybased population: a 10-year follow-up study. Kidney Int. 2007; 71:159-66.

23. The National Health and Nutritional Survey in Japan. The National Health and Nutritional Survey in Japan, 2008. Tokyo: Dai-ichi Shuppan Co.; 2011 (in Japanese).
24. Tozawa M, Iseki K, Iseki C, Oshiro S, Ikemiya Y, Takishita S. Triglyceride, but not total cholesterol or low-density lipoprotein cholesterol levels, predict development of proteinuria. Kidney Int. 2002;62:1743-9.

25. Muntner P, Coresh J, Smith JC, Eckfeldt J, Klag MJ. Plasma lipids and risk of developing renal dysfunction: the atherosclerosis risk in communities study. Kidney Int. 2000;58:293-301.

26. Schaeffner ES, Kurth T, Curhan GC, Glynn RJ, Rexrode KM, Baigent $\mathrm{C}$, et al. Cholesterol and the risk of renal dysfunction in apparently healthy men. J Am Soc Nephrol. 2003;14:2084-91.

27. Shoji T, Abe T, Matsuo H, Egusa G, Yamasaki Y, Kashihara N, et al. Chronic kidney disease, dyslipidemia, and atherosclerosis. J Atheroscler Thromb. 2012;19:299-315.

28. Ronksley PE, Brien SE, Turner BJ, Mukamal KJ, Ghali WA. Association of alcohol consumption with selected cardiovascular disease outcomes: a systematic review and meta-analysis. BMJ. 2011;342:d671.

29. Fored CM, Ejerblad E, Fryzek JP, Lambe M, Lindblad P, Nyren $\mathrm{O}$, et al. Socio-economic status and chronic renal failure: a population-based case-control study in Sweden. Nephrol Dial Transplant. 2003;18:82-8.

30. Shoham DA, Vupputuri S, Kaufman JS, Kshirsagar AV, Diez Roux AV, Coresh J, et al. Kidney disease and the cumulative burden of life course socioeconomic conditions: the Atherosclerosis Risk in Communities (ARIC) study. Soc Sci Med. 2008; 67:1311-20.

31. Hoy WE. Renal disease in Australian aboriginals. Med J Aust. 1996; $165: 126-7$

32. Huda MN, Alam KS, Alam KS, Harun UrR. Prevalence of chronic kidney disease and its association with risk factors in disadvantageous population. Int J Nephrol. 2012;2012:267329.

33. Perkovic V, Cass A, Patel AA, Suriyawongpaisal P, Barzi F, Chadban S, et al. High prevalence of chronic kidney disease in Thailand. Kidney Int. 2008;73:473-9.

34. Japanese Society of Nephrology. The guidebook for the measurements of renal function (GFR) and protein in urine. Tokyo: Tokyo Igaku Co.; 2009 (in Japanese).

35. Iseki K, Oshiro S, Tozawa M, Iseki C, Ikemiya Y, Takishita S. Significance of hyperuricemia on the early detection of renal failure in a cohort of screened subjects. Hypertens Res. 2001;24:691-7.

36. Ohno I, Hosoya T, Gomi H, Ichida K, Okabe H, Hikita M. Serum uric acid and renal prognosis in patients with IgA nephropathy. Nephron. 2001;87:333-9.

37. Weiner DE, Tighiouart H, Elsayed EF, Griffith JL, Salem DN, Levey AS. Uric acid and incident kidney disease in the community. J Am Soc Nephrol. 2008;19:1204-11.

38. Chonchol M, Shlipak MG, Katz R, Sarnak MJ, Newman AB, Siscovick DS, et al. Relationship of uric acid with progression of kidney disease. Am J Kidney Dis. 2007;50:239-47.

39. Franchini I, Cavatorta A, Falzoi M, Lucertini S, Mutti A. Early indicators of renal damage in workers exposed to organic solvents. Int Arch Occup Environ Health. 1983;52:1-9.

40. Nuyts GD, Van Vlem E, Thys J, De Leersnijder D, D'Haese PC, Elseviers MM, et al. New occupational risk factors for chronic renal failure. Lancet. 1995;346:7-11.

41. Ekong EB, Jaar BG, Weaver VM. Lead-related nephrotoxicity: a review of the epidemiologic evidence. Kidney Int. 2006; 70:2074-84.

42. Kim Y, Lee BK. Associations of blood lead, cadmium, and mercury with estimated glomerular filtration rate in the Korean general population: analysis of 2008-2010 Korean National Health and Nutrition Examination Survey data. Environ Res. 2012;118:124-9.

43. Akesson A, Lundh T, Vahter M, Bjellerup P, Lidfeldt J, Nerbrand $\mathrm{C}$, et al. Tubular and glomerular kidney effects in Swedish 
women with low environmental cadmium exposure. Environ Health Perspect. 2005;113:1627-31.

44. Edwards JR, Prozialeck WC. Cadmium, diabetes and chronic kidney disease. Toxicol Appl Pharmacol. 2009;238:289-93.

45. Lewis GP, Coughlin LL, Jusko WJ, Hartz S. Contribution of cigarette smoking to cadmium accumulation in man. Lancet. 1972;1:291-2.
46. Mortensen ME, Wong LY, Osterloh JD. Smoking status and urine cadmium above levels associated with subclinical renal effects in U.S. adults without chronic kidney disease. Int J Hyg Environ Health. 2011;214:305-10. 